\title{
Performance Analysis of Two PV plants in Different Geographical Environment
}

\author{
Xin-Jing ZOU ${ }^{1, a,{ }^{*}}$, Fei-Fei JIANG ${ }^{1, b}$ and Hai-Tao LIU $^{1, c}$ \\ ${ }^{1}$ Full address of first author, including country \\ ${ }^{1}$ Key Laboratory of Solar Thermal Energy and Photovoltaic System, Institute of Electrical \\ Engineering, Chinese Academy of Sciences, 6\# Bei-er-tiao Zhongguancun, \\ Haidian district, Beijing, China \\ azxj@mail.iee.ac.cn, bjff@mail.iee.ac.cn,, 'Ihaitao@mail.iee.ac.cn
}

Keywords: Grid-connected PV plants, On-line monitoring system, Sensors, LabVIEW.

\begin{abstract}
This paper describes the design of an on-line monitoring system for grid-connected photovoltaic plants. The proposed system consists of a meteorological data collection system for measuring meteorological parameters (e.g. irradiance, ambient air temperature, etc.), a set of data collection boxes for measuring electrical parameters (e.g. DC and AC current, DC and AC voltage, DC and AC power, etc.) and a PC. The collected data have been transmitted to the PC by two methods, wired transmission and wireless transmission. The software of the on-line monitoring system based on LabVIEW (Laboratory Virtual Instrument Engineering Workbench) package is used to process, display and store the collected data in the PC disk. The on-line monitoring system was installed in a grid-connected photovoltaic plant for an on-site measurement in Qinghai province in China. The obtained results demonstrate that it has the ability for data collecting, processing and analyzing and it meets the measurement requirements of grid-connected PV plant.
\end{abstract}

\section{Introduction}

In recent years renewable energy application has been developing rapidly due to the shortage and environment pollution of the convention energy. Solar energy with characteristic of clean, non-pollution and inexhaustible is one of the promising renewable energy. Nowadays, Photovoltaic (PV) power generation in China has been rapid developed. There are many PV plants installed in different geographical environment with different types such as mountain land PV plants on mountain areas and water surface PV plants in warm and humid area. With the establishment of the more and more PV power plants, quality of PV plants is also becoming more and more important. The performance of these plants is one of the important questions of common concern. In this paper, the performance of two PV plants has been analyzed. One is a mountain land PV plant with capacity of $20 \mathrm{MW}$ installed on a mountain in Hebei province in north China. The other is water surface PV plant with capacity of $20 \mathrm{MW}$ in Jiangsu province in south China. A data acquisition system was used to collect and process the meteorological parameters and electrical parameters for analyzing the performance of the PV plants.

\section{Description of the PV Plants}

The main structure of the mountain land PV plant and the water surface PV plant is almost the same shown in Fig. 1. The whole plant consists of several subsystems. The structure of subsystem is shown in the dashed box. It has been designed to directly interconnect into the utility grid independently. Each subsystem is composed of the following main parts: PV array unit, inverter and grid access unit. The PV array unit consists of module strings and combiner boxes. Each module string consists of several PV modules connected in series. Several output wires of module strings are connected to the input terminal of combiner box in parallel. Several output wires of combiner are connected to the input terminal of inverter in parallel. Grid access unit consists of set-up transformers, relay protection 
devices and electric energy metering devices, etc. [1].

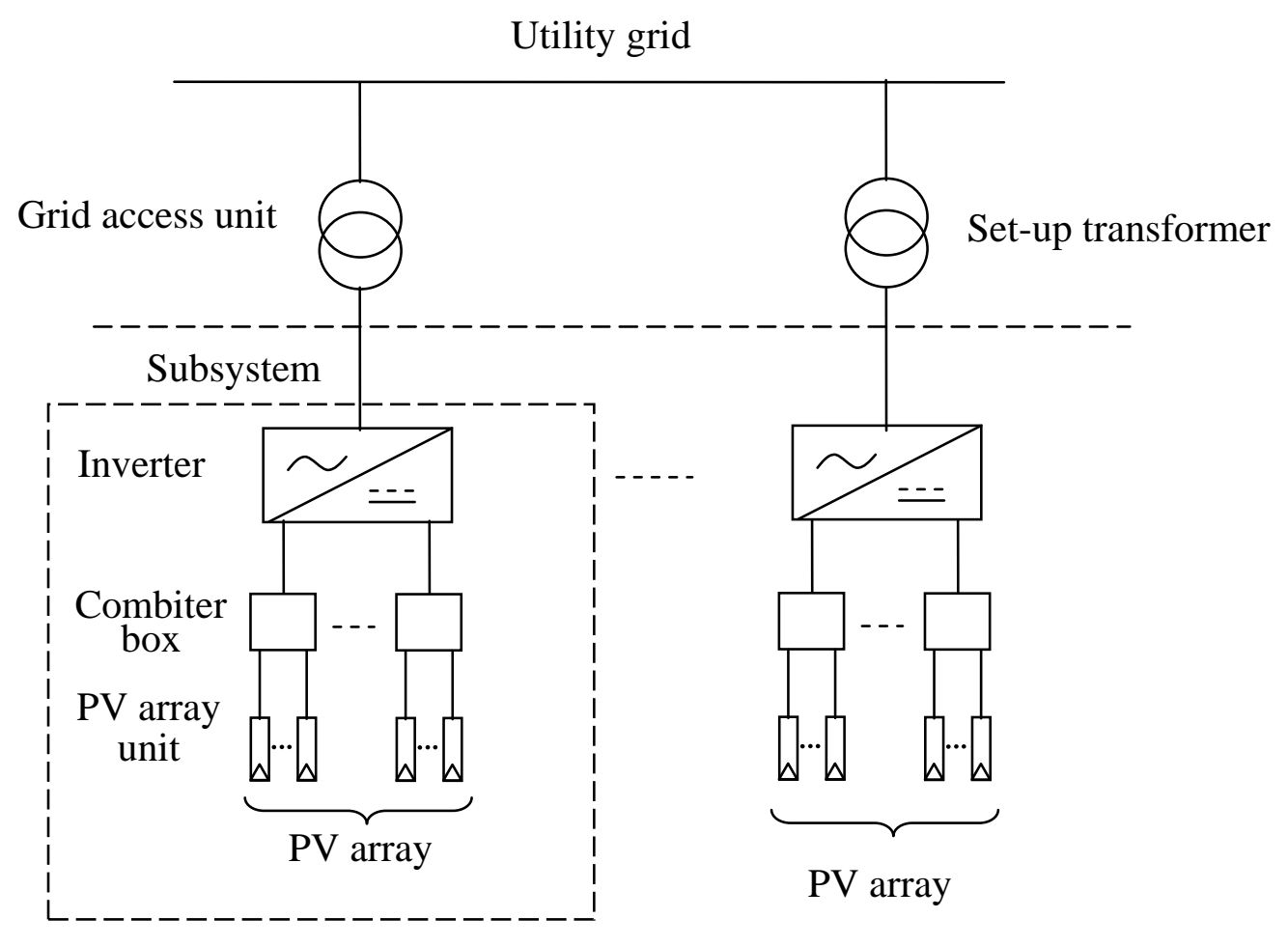

Fig. 1 Diagram of a grid-connected PV plant

Since the subsystems of each PV plant have the same structure and components no matter mountain land PV plant or water surface PV plant, we selected one of subsystems in each plant for monitoring and test.

\section{Monitoring System}

The selected subsystems were fully monitored to analysis performance by a data acquisition monitoring system [2,3]. The data acquisition monitoring system was designed to meet guideline of standard IEC 61724 [4] and within the framework of the International Energy Agency Photovoltaic Power System (IEA PVPS) Program TASK 2 [5, 6]. It was used to collect the following data: DC current and voltage, AC current and voltage, DC and AC power, output energy, module temperature, solar radiance and environment temperature.

The parameters to be measured by a data acquisition system in real time are shown in table 1 . The sampling interval for parameters is set as 5 seconds and stored as 1 minute average. All parameters were continuously measured during the specified monitoring period at a common rate. The data acquisition has been carried out for 7 days. The necessary information of the subsystem was input into the PC by the input interface.

Various derived parameters related to the PV system's energy and performance may be calculated from the recorded monitoring data using sums, averages, maxima, minima, and ratios over a specified monitoring period $\tau$, (such as days, weeks, months and years) by the data acquisition software. Derived parameters are shown in table 2. 
Table 1 Parameters to be measured in real time

\begin{tabular}{|c|c|}
\hline Parameters & Unit \\
\hline Meteorology & {$\left[\mathrm{W} / \mathrm{m}^{2}\right]$} \\
Total irradiance, in the plane of the array & {$\left[{ }^{\circ} \mathrm{C}\right]$} \\
Ambient air temperature & {$[\mathrm{m} / \mathrm{s}]$} \\
Wind speed & {$[\mathrm{V}]$} \\
\hline Module string & {$[\mathrm{A}]$} \\
Output voltage & {$[\mathrm{kW}]$} \\
Output current & {$\left[{ }^{\circ} \mathrm{C}\right]$} \\
Output power & \\
Module temperature & {$[\mathrm{V}]$} \\
Combiner box & {$[\mathrm{A}]$} \\
Output voltage & {$[\mathrm{kW}]$} \\
Output current & \\
Output power & {$[\mathrm{V}]$} \\
Inverter & {$[\mathrm{A}]$} \\
Input voltage & {$[\mathrm{kW}]$} \\
Input current & {$[\mathrm{V}]$} \\
Input power & {$[\mathrm{A}]$} \\
Output voltage & {$[\mathrm{kW}]$} \\
Output current & \\
Output power & {$[\mathrm{V}]$} \\
Utility grid & {$[\mathrm{A}]$} \\
Utility voltage & {$[\mathrm{kW}]$} \\
Current to utility grid & \\
Power to utility grid & \\
\hline
\end{tabular}

Table 2 Derived parameters and losses

\begin{tabular}{|c|c|}
\hline Parameters and losses & Unit \\
\hline Daily global irradiation, in the plane of the array & {$\left[\mathrm{kWh} / \mathrm{m}^{2} \mathrm{~d}\right]$} \\
\hline Energy from module string & {$[\mathrm{kWh}]$} \\
\hline Energy from combiner & {$[\mathrm{kWh}]$} \\
\hline Energy to PCU & {$[\mathrm{kWh}]$} \\
\hline Energy from PCU & {$[\mathrm{kWh}]$} \\
\hline Energy to utility grid & {$[\mathrm{kWh}]$} \\
\hline a PR & {$[\%]$} \\
\hline${ }^{\mathrm{b}}$ BOS loss & {$[\%]$} \\
\hline DC cable loss & {$[\%]$} \\
\hline AC cable loss & {$[\%]$} \\
\hline Other loss & {$[\%]$} \\
\hline
\end{tabular}

Note:

${ }^{\mathrm{a}} \mathrm{PR}$ : Performance Radio.

${ }^{\mathrm{b}}$ BOS :Balance of system components (inverter, DC control cabinet).

To evaluate the PV plant, PR is a very important parameter. It indicates the overall effect of losses of the plant. The following factors are considered to affect PR:

- Solar irradiation 
- Incident angle of PV array

- Mismatch losses

- BOS loss

- DC cable loss

- AC cable loss

- Shadow loss

- Dust loss

- Module power degradation

The other loss mentioned in table 2 includes the losses of solar irradiation, incident angle of PV array and all kinds of mismatch. In addition to the parameters in the table 2, there are other 3 kinds of losses used to assess the PV performance mentioned in above description. They are shadow loss, dust loss and module power degradation which are shown in table 3. Because the test for the module power degradation and dust loss needed to disconnect operation of PV plant, the data acquisition system could not be used in the test. Hence, PV IV curve tester was used to test the module power degradation and dust loss. Shadow loss can be calculated by PVsyst. It is a PC software package to design a PV system.

Table 3 Tested losses

\begin{tabular}{|c|c|}
\hline Losses & Unit \\
\hline Shadow loss & {$[\%]$} \\
\hline Dust loss & {$[\%]$} \\
\hline Module power degradation & {$[\%]$} \\
\hline
\end{tabular}

There are many reasons for shadow loss such as shadows caused by obstacles, photovoltaic array, buildings, tall vegetation, mountains, etc. Geographical location and environment of PV plants is an important factor which affects the shadow loss. Dust loss usually occurs in dry and sandy environment. Of course, without timely cleaning PV arrays will also cause greater dust loss. Module power degradation not only depends on the quality of the PV module, but also influenced by environment of the PV plant. Adverse environments will accelerate PV module decay and aging. For example, the wet and raining geographical environment will cause the PV module to produce potential induced degradation (PID) phenomenon. PID will reduce the PV module power and will cause the output energy of PV plant decreased.

\section{Performance Analysis of Two PV Plants}

\section{Analysis of Mountain land PV plant}

As shown in Fig. 2, the PR value of mountain land PV subsystem is $79.00 \%$. All kinds of losses include shadow loss, dust loss, module power degradation, BOS loss, DC cable loss, AC cable loss and other loss. The total loss value is $21.00 \%$, of which the dust loss was $5.16 \%$. It is the maximum loss in all kinds of losses. The reason for this result is due to the local geography and weather conditions. The module surface of the mountain land PV plant, which is installed in the dry and dusty mountain areas in the north China, is very likely to be covered by dust and cause the dust loss. 

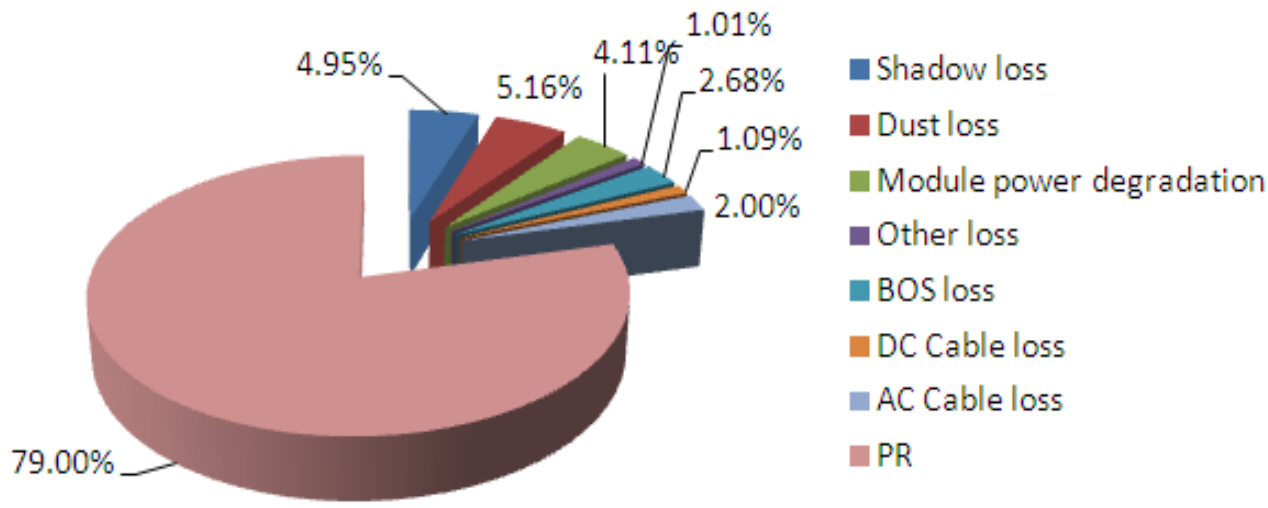

Fig. 2 Diagram of PR and various losses of mountain land PV subsystem

The value of shadow loss is $4.95 \%$. It also accounts for a large proportion of all kinds of losses. Mountain terrain is considered to be the main cause of the shadow loss. The other shadow losses are caused by trees, houses, wire rods, fences and shading between PV arrays. Fig. 3 shows the typical current curves of a module strings in a combiner box in mountain land PV subsystem. There are 10 same module strings in a combiner box. These current curves of module strings should be consistent in normal conditions. The triangle section in the Fig. 3 shows that one of current curve deviates from the other current curves. The reason for the deviation is that the module string is shaded by an object or its orientation deviates from due south. The oral section in the Fig. 3 shows that two of current curves deviate from the other current curves. The reason for the deviation is that the module strings are shaded by distant hills, hill ridge or other objects. The square section shows the fluctuation of the current curve, which is caused by the cloud cover. However, the consistency of the currents in module strings is not affected by the cloud cover. Because the loss caused by the cloud cover is caused by natural weather, it usually is not included in the calculation of the shadow loss.

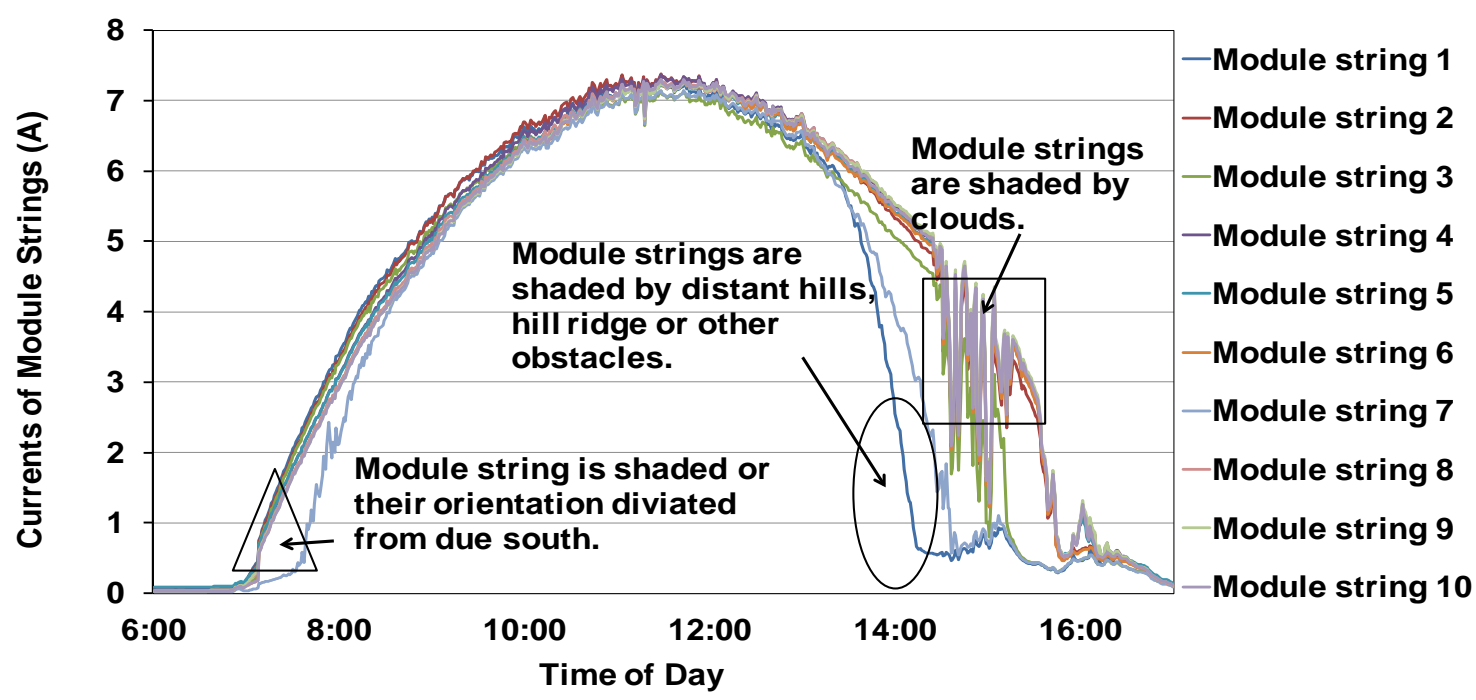

Fig. 3 Typical current curves of module strings in a combiner box in mountain land PV subsystem

The module power degradation is $4.11 \%$ shown in Fig. 2 and it is relatively high. In addition to losses mentioned above, each loss such as BOS loss, DC and AC cable loss etc., is not more than $2.68 \%$ and is relatively low in the total losses.

\section{Analysis Performance of Water Surface PV Plant}

As shown in Fig. 4, the PR value of water surface PV subsystem is $83.56 \%$. All kinds of losses include dust loss, module power degradation, BOS loss, DC cable loss, AC cable loss and other loss. The total loss value is $16.44 \%$, of which the module power degradation was $7.19 \%$. It is the maximum 
loss in all kinds of losses. The main reason for this result is considered as impact of PID. The water surface PV plant was installed on the water surface and located in humid and rainy area in south China. Humid environment caused the module to produce PID phenomenon, which led to more serious module power degradation. The dust loss is only $0.21 \%$ shown in Fig. 4 due to the wet and rainy area in south China. In addition to losses mentioned above, each loss such as BOS loss, DC and AC cable loss etc., is not more than $2.50 \%$ and is relatively small in the total losses.

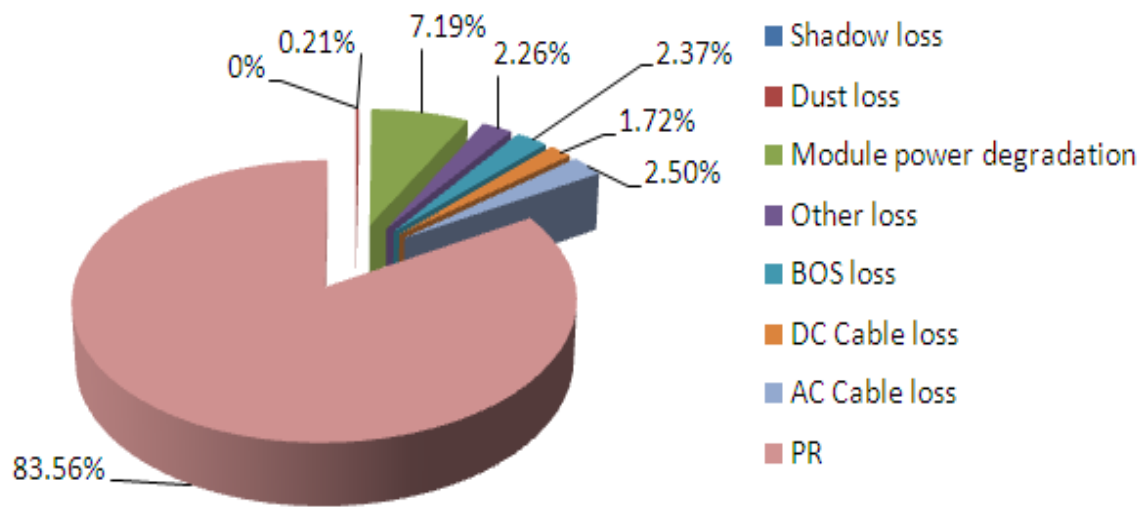

Fig. 4 Diagram of PR and various losses of water surface PV subsystem

Fig. 5 shows the typical current curves of a module strings in a combiner box in water surface PV subsystem. From the Fig. 5, we can see that all the current curves are consistent. This shows that the PV array is not shaded by objects. It is reason why the shadow loss is $0 \%$ shown in Fig. 4. Although the square section shows the fluctuation of the current curve, which is caused by the cloud cover, the consistency of the currents in module strings is not affected by the cloud cover and it usually is not included in the calculation of the shadow loss.

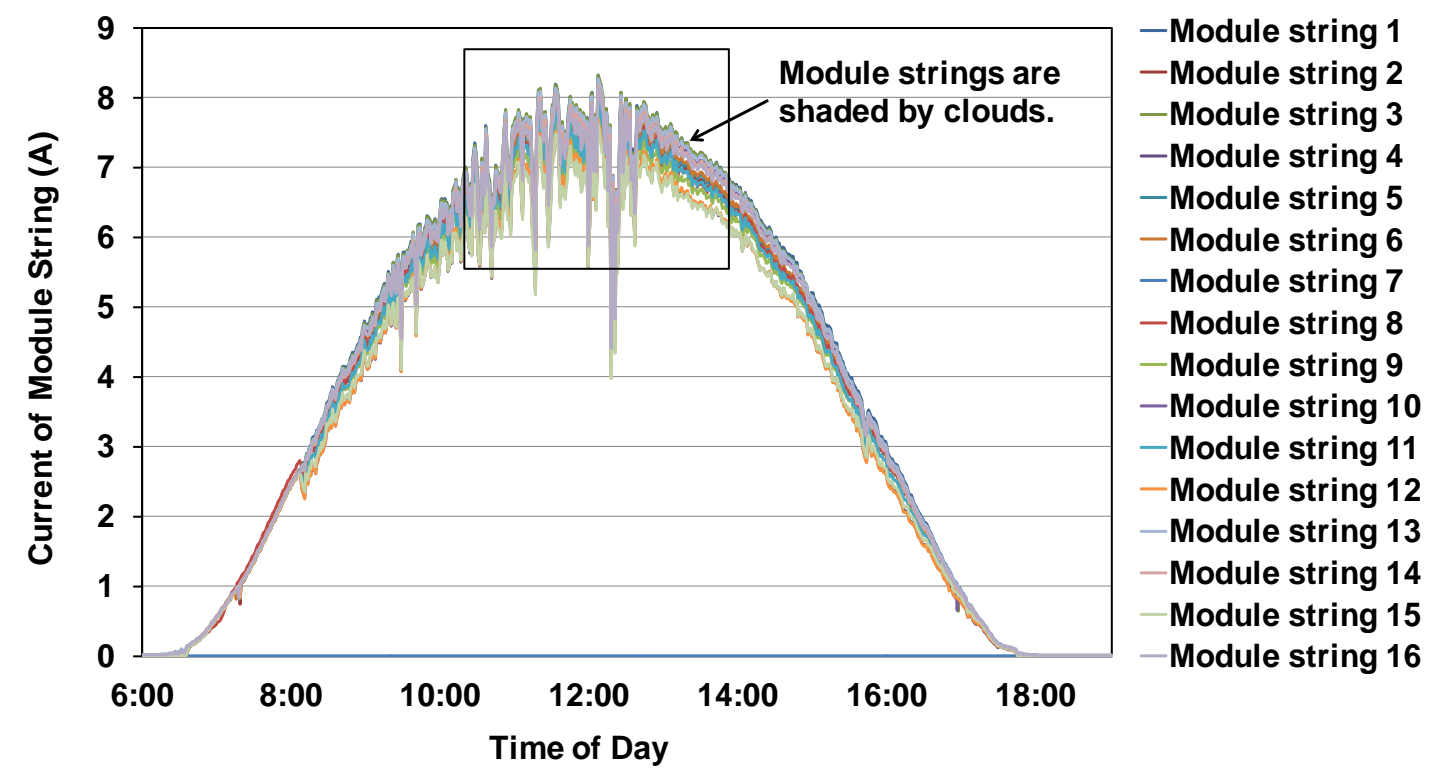

Fig. 5 Typical current curves of module strings in a combiner box in water surface PV subsystem

\section{Comparative Analysis of the Two PV plants}

The PR comparison of the mountain land PV subsystem and the water surface PV subsystem is shown in Fig. 6. It shows that PR of water surface PV subsystem is higher than that of mountain land PV subsystem. 


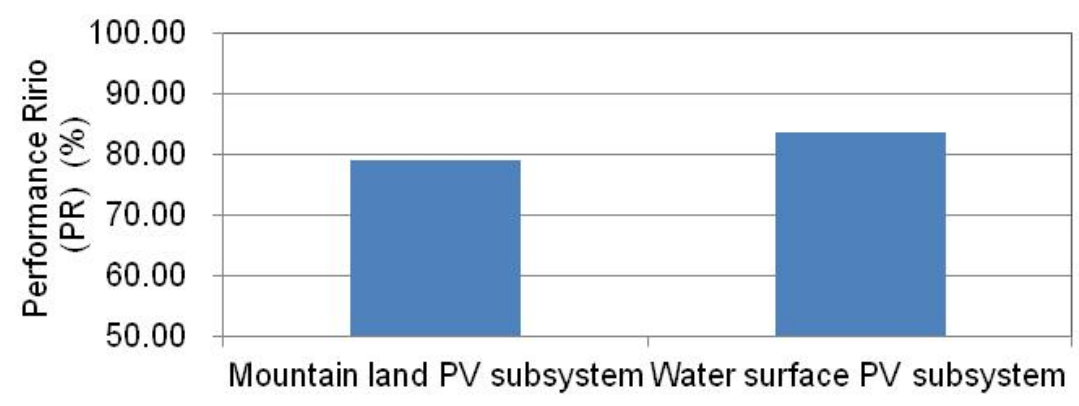

Fig. 6 PR comparison of the mountain land PV subsystem and the water surface PV subsystem

Fig. 7 shows that the losses comparison of the mountain land PV subsystem and the water surface PV subsystem. It shows that the shadow loss of mountain land PV subsystem is high but that of water surface PV subsystem is zero. This is because the former is caused by distant hill shading, hill ridges shading, orientation of hill and shading by other objects while the latter is not shaded by anything. The dust loss of mountain land PV subsystem is much higher than that of water surface subsystem because the plant is in the dry and windy area. The module power degradation of water surface PV subsystem is higher than that of mountain land PV subsystem. The increase of the former is due to add the loss caused by the PID on the basis of the natural degradation of module. In addition to the above losses, other losses such as BOS loss, DC and AC cable losses of the two subsystems are no significant difference as shown in Fig. 7.

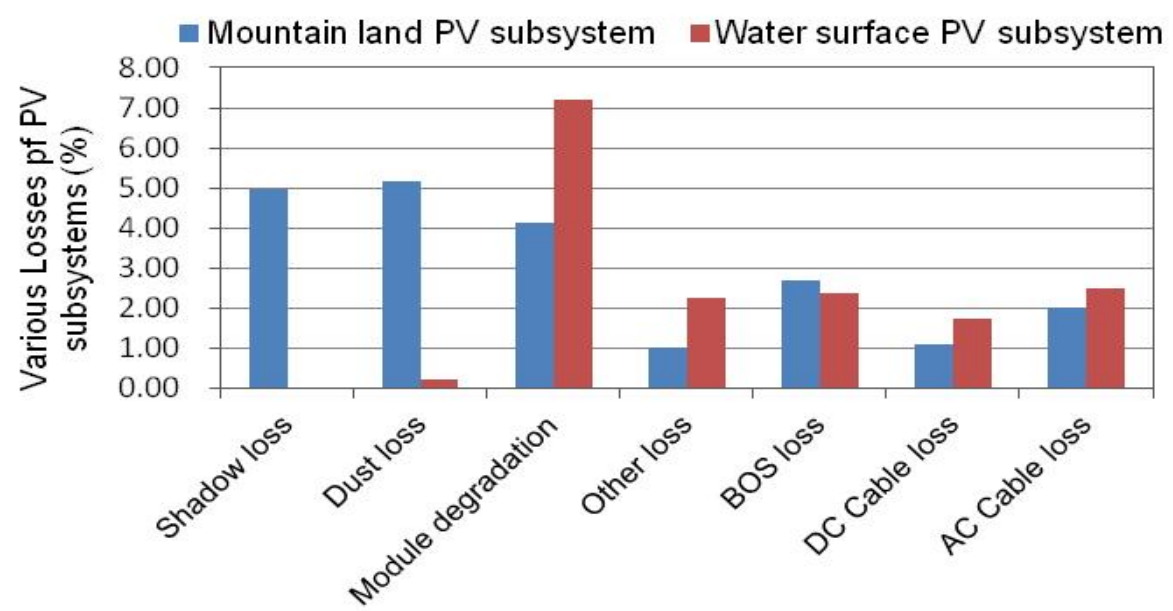

Fig. 7 Losses comparison of the mountain land PV subsystem and the water surface PV subsystem

\section{Conclusion}

The performances of a mountain land PV plant and a water surface PV plant are analyzed. The results show that the PR of the mountain land PV subsystem and the water surface PV subsystem are $79.00 \%$ and $83.56 \%$, respectively. The PR of the water surface PV subsystem is higher than that of the mountain land PV subsystem. The shadow loss, dust loss and module power degradation of the mountain power plant are 4.95, 5.16\% and 4.11\% respectively, while those of the water surface subsystem are $0 \%, 0.21 \%$ and $7.19 \%$. It showed that main losses of mountain land PV subsystem are shadow loss and dust loss while the main loss of water surface PV subsystem is module power degradation. The main cause of the shadow loss and dust loss of mountain land PV subsystem are considered as the mountain terrain and dry sandy climate in north China while the main reason of the module power degradation of water surface PV subsystem is mainly caused by PID in humid environment in south China. 


\section{Acknowledgement}

This work is supported by National Science and technology support program of Ministry of Science and Technology of China under contract No.2015AA050301.

\section{References}

[1] X. J. Zou, B. Li, Y. H. Zhai, Performance of a grid-connected BIPV system at Jiangsu province, China, IEEE PES Asia-Pacific Power and Energy Engineering Conference, (Tianjin, China, 2012).

[2] X. J. Zou, B. Li, Development of a data acquisition system for grid-connected photovoltaic systems, in International Conference on Electrical and Control Engineering, Vol.6, pp. 5227-5230, (Yichang, China, 2011).

[3] X. J. Zou, B. Li, Y. H. Zhai, Design of on-line monitoring system for grid-connected photovoltaic power plants, Applied Mechanics and Materials, Vol.303-306, 431-434, 2013.

[4] IEC, Photovoltaic System Performance Monitoring Guidelines for Measurement, Data Exchange, and Analysis, IEC Standard 61724, (Geneva, Switzerland, 1998).

[5] U. Jahn, D. Mayer, International energy agency PVPS TASK2: analysis of the operational performance of the IEA database PV systems. In: 16th European photovoltaic solar energy conference and exhibition, (Glasgow, United Kingdom, 2000).

[6] J. Ulrike, G. Bodo, Task2 operational performance of PV systems and subsystems, IEA-PVPS, Report IEA-PVPS T2-01, (2000). 